\title{
First line treatment of advanced non-small- cell lung cancer - specific focus on albumin bound paclitaxel
}

This article was published in the following Dove Press journal:

International Journal of Nanomedicine

24 December 2013

Number of times this article has been viewed

\section{Neha Gupta \\ Hassan Hatoum \\ Grace K Dy}

Department of Medicine, Roswell Park Cancer Institute, Buffalo, NY, USA
Correspondence: Grace Dy Department of Medicine, Roswell Park Cancer Institute, Elm and Carlton Streets, Buffalo, NY | 4263, USA

Tel + I 7168453099

Fax + I 7I68453935

Email grace.dy@roswellpark.org
Abstract: Lung cancer is the leading cause of cancer mortality worldwide in both men and women. Non-small-cell lung cancer (NSCLC) is the most common type of lung cancer, accounting for more than $80 \%$ of cases. Paclitaxel has a broad spectrum of activity against various malignancies, including NSCLC. Paclitaxel is poorly soluble in water and thus, until recently, its commercially available preparations contained a non-ionic solvent Cremophor EL ${ }^{\circledR}$. Cremophor $\mathrm{EL}^{\circledR}$ improves the solubility of paclitaxel and allows its intravenous administration. However, certain side-effects associated with paclitaxel, such as hypersensitivity reactions, myelosuppression, and peripheral neuropathy, are known to be worsened by Cremophor ${ }^{\circledR}$. Nanoparticle albumin-bound paclitaxel ([nab-paclitaxel] ABRAXANE ${ }^{\circledR}$ ABI-007) is a new generation formulation of paclitaxel that obviates the need for Cremophor ${ }^{\mathbb{R}}$, resulting in a safer and faster infusion without requiring the use of premedications to avoid hypersensitivity. Albumin-binding receptor-mediated delivery and lack of sequestering Cremophor ${ }^{\circledR}$ micelles allow higher intratumoral concentration of pharmacologically active paclitaxel. Multiple clinical trials have demonstrated a superior tolerability profile of nab-paclitaxel in comparison to solvent-bound paclitaxel (sb-paclitaxel). A recent Phase III trial compared the effects of weekly nab-paclitaxel in combination with carboplatin versus sb-paclitaxel in combination with carboplatin given every 3 weeks for first line treatment of NSCLC. This trial highlights the weekly nab-paclitaxel combination as an alternate treatment option for NSCLC, with higher response rate in squamous cell NSCLC and longer survival in elderly patients. This review will focus on the properties of nab-paclitaxel and its use in the first line treatment of NSCLC.

Keywords: ABI-007, Abraxane, nab-paclitaxel, lung neoplasms

\section{Introduction}

Lung cancer is the second most common cancer and the leading cause of cancer death globally in men and women. ${ }^{1}$ Approximately 159,480 lung cancer-related deaths are estimated to occur in 2013 in the United States. ${ }^{1}$ About $80 \%-85 \%$ of lung cancers are non-small-cell lung cancer (NSCLC), which include adenocarcinoma, squamous cell carcinoma, large cell carcinoma, and unclassified NSCLC. Seventy percent of patients present with advanced stage disease, where response rate to current standard combination chemotherapy is only $20 \%-25 \%$ and median survival is $10-12$ months. $^{2}$ These statistics demonstrate an unmet need for novel treatment approaches in metastatic NSCLC. Third generation chemotherapy agents (paclitaxel, docetaxel, gemcitabine, pemetrexed, or vinorelbine) in combination with a platinum compound (cisplatin, carboplatin) are the most commonly used backbone regimens for the first line treatment of advanced NSCLC. ${ }^{3}$ The use of taxanes (especially paclitaxel) is 
complicated by toxicities and solubility issues. Paclitaxel is a very hydrophobic compound, and the initial US Food and Drug Administration (FDA)-approved formulation used Cremophor $\mathrm{EL}^{\circledR}$ ([CrEL] polyoxyethylated castor oil [Merck Millipore, Billerica, MA, USA]) and ethanol as its vehicle for parenteral administration. ${ }^{4} \mathrm{CrEL}$ is primarily responsible for many side effects observed with solvent-bound (sb)paclitaxel. CrEL can lead to: 1) an acute hypersensitivity reaction, requiring premedication with antihistamines or corticosteroids; 2) leaching of plasticizers from polyvinyl chloride (PVC) bags, necessitating the use of non-PVC infusion systems; 3) potentiation of myelosuppressive and neurotoxic side effects of paclitaxel, limiting the dose increments of taxanes; and 4) entrapment of paclitaxel in plasma within CrEL micelles, resulting in suboptimal delivery of the drug to the tumor itself. ${ }^{5-7}$ The introduction of nanoparticle albumin-bound paclitaxel (nab-paclitaxel) provides an exciting alternative to sb-paclitaxel. ${ }^{4} \mathrm{Nab}$-paclitaxel gained its initial FDA approval for metastatic breast cancer patients who failed combination chemotherapy (based on the results of Phase III trial by Gradishar et al). ${ }^{8}$ It was first introduced into the market in 2005. Nab-paclitaxel combination with carboplatin was recently FDA approved in October 2012 for the first-line treatment of patients with locally advanced or metastatic NSCLC unfit for surgery or radiation therapy. Nabpaclitaxel in combination with gemcitabine is currently under FDA priority review for the frontline treatment of metastatic pancreatic cancer. In this article, we provide a brief summary of the development of nab-paclitaxel with an emphasis on its clinical development in NSCLC.

\section{Brief synopsis of nab-paclitaxel}

Nab-paclitaxel is a novel $130 \mathrm{~nm}$-albumin bound CrEL-free preparation of sb-paclitaxel. ${ }^{4}$ It is synthesized by highpressure homogenization of paclitaxel in the presence of serum albumin. This process leads to formation of a nanoparticle colloidal suspension of paclitaxel at an albumin concentration of 3\%-4\%. ${ }^{9}$ As opposed to the 3-hour infusion time of sb-paclitaxel, nab-paclitaxel is usually infused over a much shorter time (30 minutes). Short infusion time is possible due to nab-paclitaxel's smaller reconstituted volume and reduced risk of hypersensitivity reactions. Figure 1 shows a pictorial representation of albumin-bound paclitaxel.

Hypersensitivity reactions seen with sb-paclitaxel are thought to be mediated via Cremophor ${ }^{\circledR}$. Even though it has not been unequivocally proven in literature, findings from multiple studies point towards the plausibility of this hypothesis. ${ }^{10,11}$ The reduced hypersensitivity reactions with

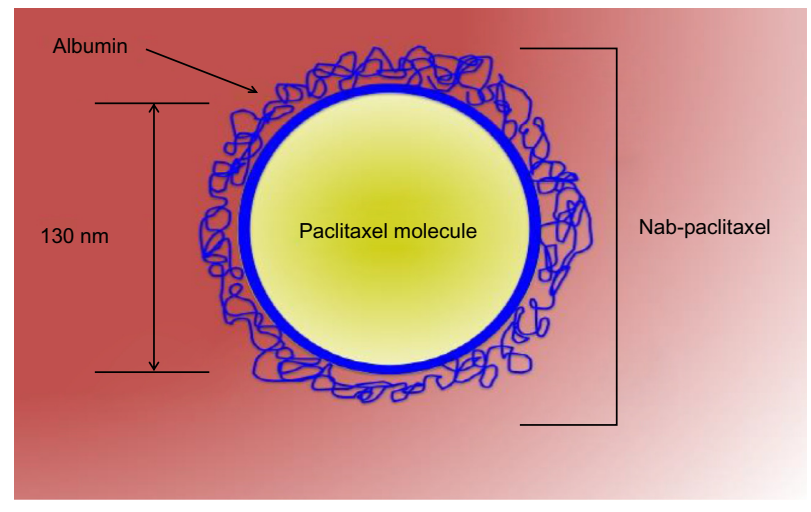

Figure I Graphic representation of nanoparticle albumin-bound paclitaxel (nabpaclitaxel).

use of nab-paclitaxel are most likely a result of the absence of Cremophor ${ }^{\circledR}$ vehicle in this formulation. Genetaxyl, a paclitaxel formulation that contains reduced levels of CrEL, also shows significantly lower hypersensitivity reactions in comparison to standard taxol. ${ }^{12}$

Nab-paclitaxel primarily acts like sb-paclitaxel, by disrupting the microtubular network and inhibiting the cell division. This mechanism is popularly termed as "frozen mitosis." In addition, nab-paclitaxel also has an interesting mechanism to augment paclitaxel delivery to the tumor cells, thus providing a distinct advantage over sb-paclitaxel. Nab-technology utilizes albumin to transport paclitaxel directly to the cancer cells via receptor-mediated transport mechanism. ${ }^{13}$ Active transport of albumin across microvessel endothelial cells occurs via gp60 receptor and subsequent caveolae formation. ${ }^{14,15}$ Albumin binding to gp60 receptor on endothelial cells activates caveolin-1, leading to formation of vesicles (caveolae) which further transport the albumin-drug complex across the endothelial cells into the tumor interstitial space. ${ }^{15,16}$ As a result, nab-paclitaxel allows ten-fold increase in the binding of paclitaxel to endothelium, four-fold increase in the transport of paclitaxel across endothelial cell monolayers, and 33\% increase in intratumoral accumulation of paclitaxel. ${ }^{13}$ Small particle size of the drug perhaps plays a role in making the transport of nab-paclitaxel across biological membranes easier and faster, thus leading to more effective drug transport to tumor cells. Since tumors are surrounded by multiple leaky capillaries with gaps in the range of 100-800 nm in length, passage of $130 \mathrm{~nm}$-size particles is easily allowed. Decreased risk of capillary blockage by the small size of nab-paclitaxel may also contribute to overall improved delivery to tumors. Nab-paclitaxel also increases the free paclitaxel fraction in plasma as compared to sbpaclitaxel since it is devoid of CrEL-induced entrapment of 
paclitaxel within micelles. ${ }^{7,17}$ Cremophor ${ }^{\circledR}$ prevents paclitaxel distribution out of the vascular compartment into the tissues. This is because micelles, unlike unbound paclitaxel, are neither capable of interacting with endothelial receptors nor diffusing across biological membranes. In contrast, albuminbound paclitaxel is transported as a complex via endothelialreceptor mediated endocytosis and also across the biological cell membranes. Figure 2 shows the mechanism of delivery of nab-paclitaxel across the tumor microenvironment.

Higher intratumoral uptake of nab-paclitaxel may, in part, be a result of overexpression of matricellular albuminbinding protein (secreted protein acidic and rich in cysteine [SPARC]) in some malignancies. ${ }^{18,19}$ SPARC (also called as osteonectin or basement membrane protein 40) is a nonstructural matricellular calcium-binding glycoprotein usually suppressed in mature human tissues. SPARC is involved in cell-matrix interaction during tissue remodeling and embryonic development. In SPARC-negative NSCLC cells, SPARC gene undergoes promoter region hypermethylation, resulting in loss of expression. ${ }^{20}$ In SPARC-positive NSCLC, SPARC is selectively synthesized by the peritumoral stromal fibroblasts in the tumor microenvironment, with minimal production by the tumor cells themselves. ${ }^{21}$ The stromal SPARC expression is strongly associated with markers of intratumoral hypoxia and acidity, indicating a possible role in cancer cell invasion. SPARC overexpression in peritumoral stroma is associated with poor prognosis in some tumors including NSCLC, pancreatic cancer, and ovarian cancer. ${ }^{21-23}$ Interestingly, the repression of SPARC expression in tumor cells by gene hypermethylation is also associated with poor outcome. Additionally, the induction of SPARC expression in tumor cells exhibits antiproliferative effects in some models. ${ }^{24}$ The disparate effects of SPARC expression may result from an interplay of a complex autocrine and/or paracrine mechanism of simultaneous selective downregulation in tumor cells accompanied by selective upregulation in adjacent stromal cells. The context-dependent SPARC signaling along with a lack of a reproducible assay underlie the difficulty in validating the role of SPARC as a biomarker of response to nab-paclitaxel, not to mention the added layer of complexity in predicting tumor response to paclitaxel itself. While the expression of SPARC is shown to correlate with antitumor response of nab-paclitaxel in head and neck cancer, such a correlation

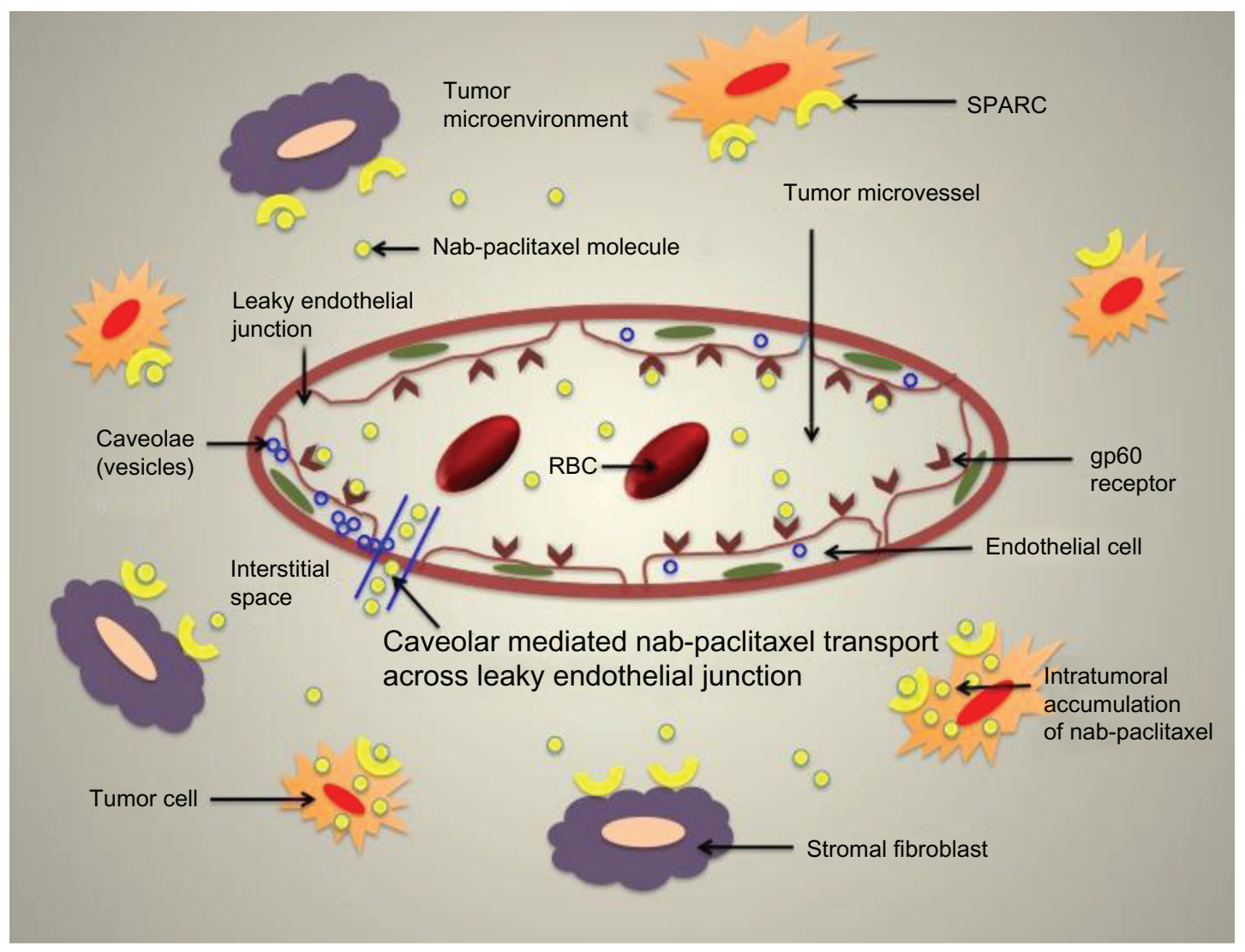

Figure 2 Transport of nab-paclitaxel across tumor microenvironment.

Abbreviations: SPARC, secreted protein, acidic and rich in cysteine; gp60 receptor, glycoprotein 60 receptor; RBC, red blood cell. 
could not be found in a preclinical evaluation of patientderived xenografts in NSCLC. ${ }^{20,25}$

\section{Preclinical properties of nab-paclitaxel}

Desai et al studied the preclinical properties of nab-paclitaxel using cell lines from five human solid tumors, ie, lung (H522), breast (MX-1), ovarian (SK-OV-3), prostate (PC-3), and colon (HT29). ${ }^{13}$ These cell lines were propagated in vivo as solid tumors after subcutaneous implantation of tumors in female athymic nude mice. The investigators performed in vitro binding and transport studies and in vivo studies pertaining to antitumor activity, toxicity, and intratumor paclitaxel concentration. Median lethal doses for nab-paclitaxel and sb-paclitaxel were $47 \mathrm{mg} / \mathrm{kg} /$ day and $30 \mathrm{mg} / \mathrm{kg} /$ day, respectively. Mortality in the nab-paclitaxel group was considerably lower in comparison to sb-paclitaxel at $30 \mathrm{mg} / \mathrm{kg} /$ day dose (4\% versus 49\%, respectively). Maximum tolerated dose (MTD) for nab-paclitaxel and sb-paclitaxel were $30 \mathrm{mg} / \mathrm{kg} /$ day and $13.4 \mathrm{mg} / \mathrm{kg} /$ day, respectively, and these doses were also equitoxic with $4 \%$ mortality in each group. Out of the five tumor cell lines, the lung tumor xenograft was the most sensitive to both drug formulations, producing maximum antitumor activity. Maximum tumor free survival, longest tumor doubling times, and lowest tumor volumes were seen with lung cancer. The order of sensitivity was lung $>$ breast $=$ ovary $>$ prostate $>$ colon. Even though the mean lung tumor volumes were lower in nab-paclitaxel when compared to sb-paclitaxel, this difference was not statistically significant and neither was the difference in any other measure of antitumor activity. Significant difference between the two formulations of paclitaxel was, however, observed in the other four tumor xenografts. Maximum difference between the two drugs was seen in breast and ovarian tumor xenografts. When studied at equitoxic dose, nab-paclitaxel treatment resulted in comparatively greater tumor volume regression, median time to tumor recurrence, tumor doubling time, and higher percentage of tumor-free survivors.

With equal doses of paclitaxel, partitioning of drug into the tumor tissue was much more rapid with nab-paclitaxel with an absorption constant 3.3-fold greater than sb-paclitaxel. Apparent difference in intratumor paclitaxel concentration was seen at the first time point sampled ( 5 minutes), which became maximal at the 3-hour sampling point. Overall, the tumor paclitaxel area under the curve (AUC) was 33\% higher for nab-paclitaxel compared to sb-paclitaxel. The authors also performed the in vitro endothelial cell binding and transport studies to investigate the potential mechanisms for increased intratumor paclitaxel concentration. Endothelial cell binding of paclitaxel was 9.9-fold higher and transport of paclitaxel across an endothelial cell monolayer was 4.2-fold higher with nab-paclitaxel. These experiments were performed on human umbilical vascular endothelial cells and human lung microvessel endothelial cells. An inhibitor of caveolaemediated transcytosis, methyl $\beta$-cyclodextrin, completely suppressed endothelial transcytosis of nab-paclitaxel. With progressively higher doses of CrEL, endothelial cell binding of sb-paclitaxel was increasingly inhibited (inhibitory concentration $50\left[\mathrm{IC}_{50}\right] 0.010 \%$ ), with complete inhibition occurring at CrEL concentration of $0.1 \%$. Similar inhibition by CrEL was also noticed for paclitaxel binding to albumin $\left(\mathrm{IC}_{50} 0.0017 \%\right)$; this occurred at a CrEL level much below clinically relevant concentration.

$\mathrm{Ng}$ et al showed in their in vitro experiment that clinically relevant concentrations of CrEL nullifies the antiangiogenic activity of paclitaxel. ${ }^{26}$ However, the same group of investigators in another in vitro study with nab-paclitaxel demonstrated significant inhibition of rat aortic proliferation, human umbilical vascular endothelial cell proliferation, and tube formation, implicating much improved antiangiogenic activity of nab-paclitaxel when compared to sb-paclitaxel. ${ }^{27}$

\section{Other tumors: SPARC expression and role of nab-paclitaxel}

Besides NSCLC, studies have reported tumor associated SPARC overexpression in various other malignancies. These include malignancies of esophagus, ${ }^{28,29}$ stomach, ${ }^{30-32}$ pancreas, ${ }^{22,33}$ breast, ${ }^{34,35}$ ovaries, ${ }^{36}$ urinary bladder, ${ }^{37}$ head and neck, ${ }^{25}$ and melanomas. ${ }^{38}$ In studies testing SPARC expression in these tumors, SPARC was frequently immunolocalized in stromal fibroblasts but tumor cells did not overexpress SPARC. In the above mentioned malignancies, SPARC is rather underexpressed in tumor cells in comparison to normal tissue. Various authors have reported the impact of SPARC overexpression in tumor stroma on effectiveness of chemotherapy. ${ }^{39,40}$ Higher level of stromal SPARC expression in tumors may lead to chemotherapy failure due to increased "activated fibroblasts." 41 These activated fibroblasts lead to the formation of dense stroma that prevents the penetration of chemotherapeutic agents. ${ }^{41}$ However, tumors with stromal SPARC overexpression respond better to albumin-bound paclitaxel. Due to SPARC protein's property to easily bind albumin, albumin-bound paclitaxel penetrates the tumor better in comparison to other chemotherapeutic agents. Nab-paclitaxel, therefore, has a potential to be effective in 
SPARC (stromal) overexpressing tumors, which are usually associated with poor prognosis. As mentioned earlier, some preliminary studies involving breast cancer and head and neck cancer have proved this hypothesis by showing a direct correlation with level of SPARC expression and tumor response to treatment with nab-paclitaxel. Future studies are warranted to confirm these findings and to investigate how other SPARC overexpressing tumor types, like gastrointestinal, ovarian, bladder, and melanomas, respond to treatment with nab-paclitaxel.

\section{Clinical studies}

\section{Phase I and pharmacokinetic studies}

Summaries of the safety and efficacy endpoints reported in the trials discussed below are presented in Tables 1 and 2. The first Phase I trial of nab-paclitaxel used a monotherapy regimen given once every 21 days. It was performed in 19 patients with advanced solid malignancies who had disease progression following standard treatment. Dexamethasone or antihistamine premedication was not used prior to treatment with nab-paclitaxel. ${ }^{9}$ No acute hypersensitivity reactions were noticed. Sensory neuropathy, stomatitis, and superficial keratopathy were the dose limiting toxicities (DLT) observed in this study. Most adverse effects were dose-dependent. MTD of nab-paclitaxel was found to be $300 \mathrm{mg} / \mathrm{m}^{2}$ infused over 30 minutes every 3 weeks. In comparison, the extent of hypersensitivity reactions in the absence of routine premedication and with short infusion courses constituted a treatmentlimiting toxicity in the early development of sb-paclitaxel. ${ }^{42}$ In addition, the MTD of sb-paclitaxel when administered with hypersensitivity premedications was $225 \mathrm{mg} / \mathrm{m}^{2}$ infused over 6 hours once every 3 weeks. ${ }^{43}$

Another Phase I study of nab-paclitaxel monotherapy explored a different schedule of weekly drug administration, ie, three once-weekly doses, followed by 1 week off treatment, repeated every 4 weeks. ${ }^{44}$ In this study, 39 patients with advanced nonhematologic malignancies received nab-paclitaxel without premedication at doses ranging from $80 \mathrm{mg} / \mathrm{m}^{2}$ to $200 \mathrm{mg} / \mathrm{m}^{2}$ as a 30 -minute infusion. Patients were divided into two groups according to their prior treatment history. Patients were considered to be heavily pretreated (HP) if they had received one or more of the following: $\geq$ six cycles of an alkylating agent; $\geq$ two cycles of carboplatin or mitomycin; irradiation of $>25 \%$ of bone marrow-containing areas; any nitrosoureas; high-dose therapy requiring bone marrow transplantation or peripheral stem-cell support; or $>$ one cycle of an investigational agent known to cause cumulative toxicity. Also, patients with widely metastatic bone disease, with or without marrow involvement, were considered HP. Patients not meeting any criteria for HP were considered to be lightly pretreated. MTD and DLTs in HP patients were $100 \mathrm{mg} / \mathrm{m}^{2}$ and grade 4 neutropenia, respectively. MTD in lightly pretreated patients was $150 \mathrm{mg} / \mathrm{m}^{2}$ and DLT was grade 3 peripheral neuropathy. Partial responses were observed in five patients with lung, breast, and ovarian cancers, all of whom were previously treated with sb-paclitaxel.

An evaluation of effects of nab-paclitaxel as a combination chemotherapy in thoracic malignancies was reported by Stinchcombe et al. ${ }^{45}$ This Phase I study investigated the combination of nab-paclitaxel with gemcitabine and included patients with NSCLC $(n=8)$, small-cell lung cancer $(n=6)$, and esophageal cancer $(n=1)$, who had received $\leq$ three prior cytotoxic chemotherapy regimens. DLTs in the study were neutropenia, rash/pruritus, and fatigue/anorexia. MTD was determined to be nab-paclitaxel $300 \mathrm{mg} / \mathrm{m}^{2}$ on day 1 in combination with gemcitabine $1,000 \mathrm{mg} / \mathrm{m}^{2}$ on days 1 and 8 every 21 days.

Difference in the formulation of paclitaxel also impacts its clinical pharmacokinetic features. Aggregate results from the Phase I studies of nab-paclitaxel demonstrated a large volume of distribution ( $\mathrm{Vd}$ ), suggesting extensive extravascular distribution and tissue binding. ${ }^{9,17,46}$ The mean AUC increases proportionately with the increase in dose of nab-paclitaxel, implicating linear pharmacokinetics. ${ }^{9}$ In contrast, sb-paclitaxel has a nonlinear pattern of pharmacokinetics. ${ }^{9,47}$ In the Phase I study by Ibrahim et al, authors report slightly lower mean AUC in nab-paclitaxel when compared to sb-paclitaxel. ${ }^{9}$ The entrapment of paclitaxel within CrEL micelles is apparently the reason for the much smaller $\mathrm{Vd}$, nonlinear pharmacokinetics, and higher AUC of sb-paclitaxel. ${ }^{17,48}$ With increase in the dose of sbpaclitaxel, a greater proportion of paclitaxel is entrapped within CrEL micelles and, therefore, less free drug is available for elimination. ${ }^{49}$ This leads to poor clearance and higher systemic toxicities from prolonged exposure to the drug in case of sb-paclitaxel. Nab-paclitaxel has a mean drug clearance and Vd of approximately $21 \mathrm{~L} /$ hour $/ \mathrm{m}^{2}$ and $660 \mathrm{~L} / \mathrm{m}^{2}$, respectively, both of which are about $50 \%$ higher than those of sb-paclitaxel. ${ }^{17}$ However, the terminal half-life of nabpaclitaxel is no different than sb-paclitaxel (approximately 21 hours for both). ${ }^{17}$ Phase I studies of nab-paclitaxel also report a higher MTD compared to sb-paclitaxel $\left(300 \mathrm{mg} / \mathrm{m}^{2}\right.$ as a 30 minute infusion given every 21 days versus $250 \mathrm{mg}$ / $\mathrm{m}^{2}$ as a 3 hour infusion given every 21 days, respectively). ${ }^{9}$ The higher MTD in nab-paclitaxel is a reflection of its improved safety profile. 


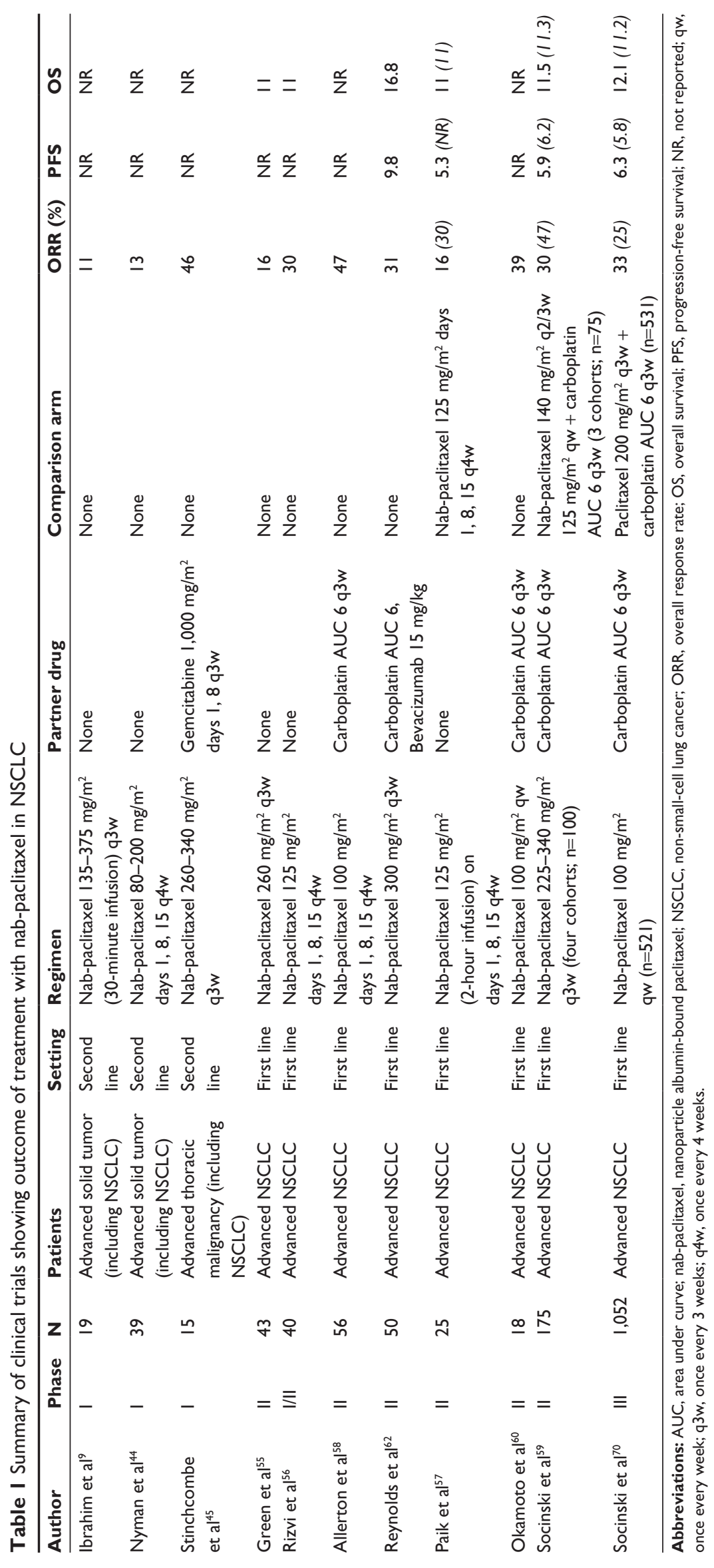




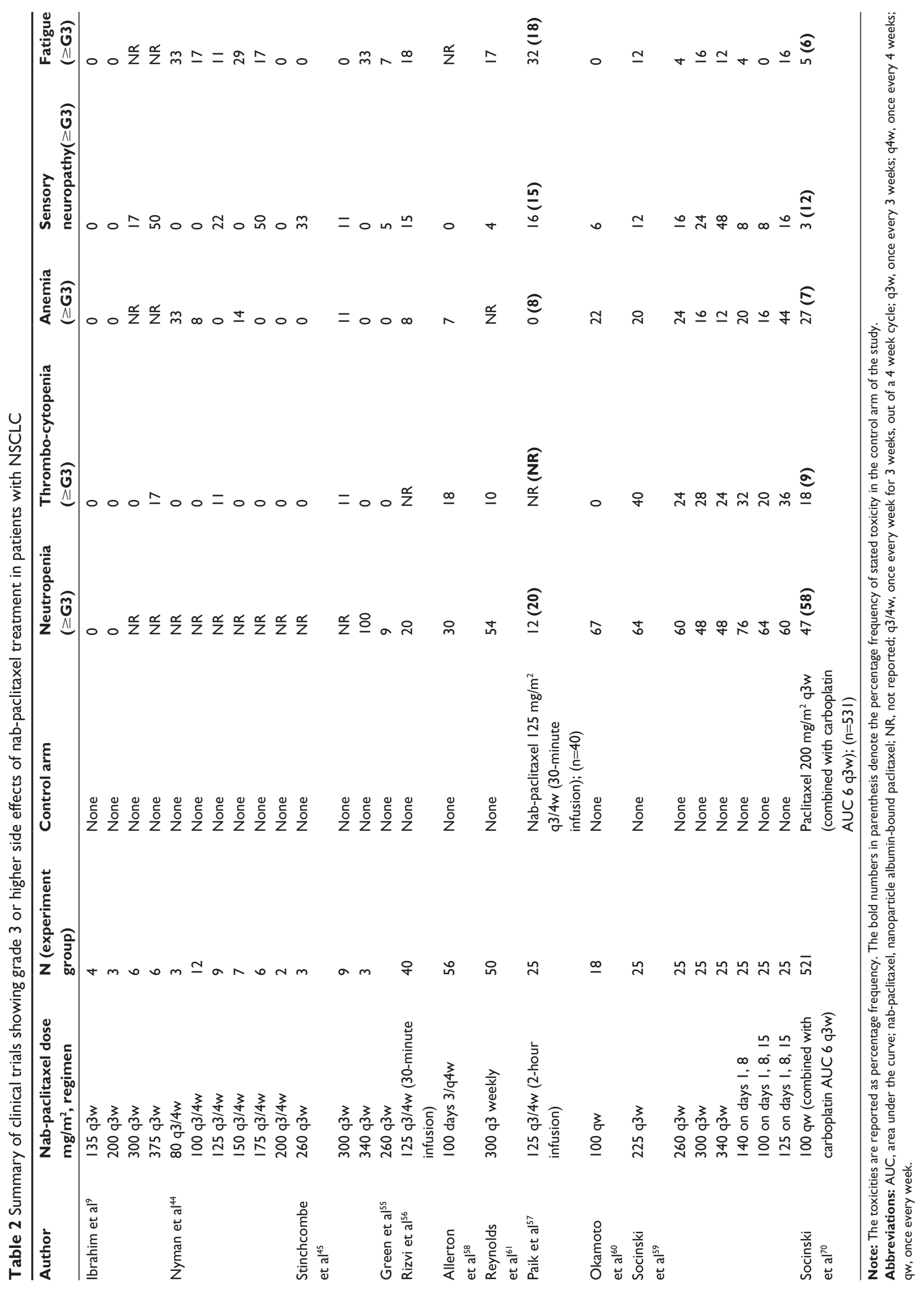


Cytochrome P450 system is involved in metabolism of nab-paclitaxel, similar to all other taxanes. ${ }^{50}$ Since nab-paclitaxel is largely metabolized by CYP2C8, it theoretically possesses a high likelihood of multiple drug-drug interactions. For example, pegylated liposomal doxorubicin has been shown to produce higher plasma levels when coadministered with paclitaxel. ${ }^{51}$ However, one should remember that, in the setting of lack of direct confirmatory drug interaction studies of nab-paclitaxel, these interactions are only based on assumption from extrapolation of paclitaxel interactions. Moreover, the drug-drug interaction may not always be clinically relevant (eg, minimal pharmacokinetic changes from clindamycin-paclitaxel combination and minimally increased plasma paclitaxel when given in combination with pazopanib). ${ }^{52,53}$ In patients with hepatic dysfunction, the same dose modification scheme recommended for sb-paclitaxel is safe and feasible for nab-paclitaxel. ${ }^{54}$

\section{Phase Ib/ll studies}

The initial Phase II nab-paclitaxel monotherapy study investigated the efficacy and safety of $260 \mathrm{mg} / \mathrm{m}^{2}$ administered every 3 weeks as first-line therapy in patients with NSCLC. ${ }^{55}$ This study included 43 patients and showed overall response rate (ORR) of $16 \%$, disease control rate of $49 \%$, median time to progression (TTP) of 6 months, and median overall survival (OS) of 11 months. Despite the lack of premedication, no hypersensitivity reactions were noticed similar to previous Phase I studies. Dose reductions were not needed for $95 \%$ of patients treated. Five percent of patients discontinued the treatment owing to treatment-related toxicities whereas none of the patients had grade 4 treatment-related toxicity. In comparison, another Phase I/II study investigated nabpaclitaxel monotherapy with dose schedule of day 1,8 , and 15 of a 28 -day cycle. ${ }^{56}$ MTD was $125 \mathrm{mg} / \mathrm{m}^{2}$ and a total of 40 patients were treated at this dose. The study outcomes included ORR of $30 \%$, median TTP of 5 months, and a median OS of 11 months. Lastly, a Phase II trial of weekly nab-paclitaxel monotherapy showed that increasing the infusion time from 30-minutes to 2 hours decreased grade 2 neuropathy compared to standard 30-minute infusion (28\% versus $55 \%, P=0.04)$. The median survival of 11 months was the same for both groups. ${ }^{57}$

As it is anticipated that the combination of nab-paclitaxel with carboplatin will have synergistic antitumor efficacy, the combination of carboplatin with various schedules of nab-paclitaxel administration was evaluated by several investigators. Allerton et al presented the preliminary results in 2006 of their Phase II study on the effect of nab-paclitaxel in combination with carboplatin in 56 advanced chemotherapynaïve NSCLC patients. ${ }^{58}$ In this trial, patients received treatment with nab-paclitaxel $100 \mathrm{mg} / \mathrm{m}^{2}$ on days 1,8 , and 15 4-weekly, in combination with carboplatin AUC 63 -weekly. An ORR of $47 \%$ in 51 evaluable patients was achieved, with median TTP of 23 weeks. OS was not reported in the abstract. Toxicities were mainly hematological. Adverse effect profile showed significant grade 3 or more toxicities as neutropenia (30\%), thrombocytopenia (18\%), and anemia (7\%), but no grade 3 or 4 neuropathy. Socinski et al also conducted a dose-finding study of the combination of nab-paclitaxel with carboplatin prior to evaluation in the Phase III trial setting. ${ }^{59}$ The Phase I study enrolled 175 patients in the study sequentially into seven cohorts, each cohort consisting of seven patients. Cohorts one to four received q3-weekly (administered once every 3 weeks) nab-paclitaxel whereas cohorts five to seven received once weekly nab-paclitaxel. The most common treatment-related $\geq$ grade 3 toxicities included neutropenia (60\%), neuropathy (19\%), fatigue (9\%), and thrombocytopenia (29\%). As shown in Table 2, nab-paclitaxel at $100 \mathrm{mg} / \mathrm{m}^{2}$ weekly dose in combination with carboplatin AUC 6 was the least toxic of all the doses and schedules tested in the trial. Response rate was also found to be greater in once weekly versus q3-weekly cohorts as shown in Table 1 (47\% versus 30\%, respectively). Patients receiving $100 \mathrm{mg} / \mathrm{m}^{2}$ weekly nab-paclitaxel achieved a 47\% ORR with comparable survival endpoints. This weekly dose schedule was thus selected for further study in the Phase III trial to be discussed below. A Phase Ib study of this dose schedule was subsequently performed in a group of 18 Japanese patients with chemotherapy-naïve advanced NSCLC ${ }^{60}$ No substantial pharmacokinetic interactions were noticed in the study with the combination. Among the 18 evaluable patients, ORR of $38.9 \%$ was reported with toxicity profile similar to the ones reported by Socinski et al. ${ }^{59}$

A combination of nab-paclitaxel $300 \mathrm{mg} / \mathrm{m}^{2}$, carboplatin AUC 6, and bevacizumab $15 \mathrm{mg} / \mathrm{kg}$ every 21 days was investigated in a Phase II setting by Reynolds et al as front line treatment of advanced (stage IIIB, IV) non-squamous NSCLC. ${ }^{61}$ This study enrolled a total of 50 patients and a response rate of $31 \%$ and stable disease rate of $54 \%$. The median OS of 16.8 months and median progression-free survival (PFS) of 9.8 months reported are among the highest seen compared to other bevacizumab-combinations reported in NSCLC. ${ }^{62-67}$ Hence, one may acknowledge that these Phase II data may be skewed to show better results due to patient selection and the caveats of cross-trial comparisons. However, quality of life, using the FACT-Taxane scale, decreased significantly over the 
course of the study, except for the emotional well-being domain, which increased throughout the first five cycles of treatment. Febrile neutropenia rate of $10 \%$ was also higher than the $5 \%$ reported in carboplatin/sb-paclitaxel/bevacizumab group in Eastern Cooperative Oncology Group 4599 (ECOG 4599) study, ${ }^{62}$ and $0 \%$ in carboplatin/nab-paclitaxel in Socinski's Phase I study. Somewhat counterintuitively, the incidence of grade 3 or 4 peripheral neuropathy or thrombocytopenia was only $4 \%$ and $10 \%$, respectively, much lower in comparison to the corresponding non-bevacizumab cohort reported by Socinski et $\mathrm{al}^{59}$ treated with otherwise the same dose schedule (see Table 2). Specific outcomes in the elderly population were not reported in this study wherein median age of participants was 67 years. This is of particular relevance as subset analyses of $\geq 70$ years old patients in ECOG 4599 showed higher incidence of severe neutropenia, bleeding, and proteinuria compared to younger patients who received bevacizumab. ${ }^{68}$

Lastly, investigators at University of California Davis Center recently reported results from their Phase I/II study in frontline treatment of NSCLC. ${ }^{69}$ Regimen used was nabpaclitaxel combination with pemetrexed (a non-platinum containing regimen) and primary endpoint was ORR $\geq 25 \%$. This study closed prematurely due to difficulty in accrual, as pemetrexed was eventually approved for use in the first-line setting. At the recommended dose-schedule of pemetrexed $500 \mathrm{mg} / \mathrm{m}^{2}$ and nab-paclitaxel $260 \mathrm{mg} / \mathrm{m}^{2}$ administered once every 21 days, the Phase II portion reported a response rate of $14 \%$ with median OS of 8.7 months.

\section{Phase III study}

The pivotal Phase III prospective open label clinical trial enrolled 1,052 chemo-naive patients with stage IIIB-IV NSCLC. Patients were randomized to receive either nabpaclitaxel $100 \mathrm{mg} / \mathrm{m}^{2}$ intravenous infused over 30 minutes weekly ( $\mathrm{n}=521)$ or sb-paclitaxel $200 \mathrm{mg} / \mathrm{m}^{2}$ intravenous infused over 3 hours once every cycle, both in combination with carboplatin AUC 6 every 3 weeks $(n=531){ }^{70}$ This was a multicenter study involving patients from Russia, Ukraine, The United States, Japan, and Australia. The patients in the treatment arms were well balanced. The primary endpoint of the trial was objective ORR and the secondary endpoints were PFS and OS. The median number of cycles was six in both the treatment arms. The primary efficacy endpoint analysis showed that nab-paclitaxel achieved statistically significant ORR in all patients as compared to sb-paclitaxel (33\% versus $25 \%$, respectively; $P=0.005$ ). Nab-paclitaxel arm showed a $10 \%$ improvement in OS (12.1 months versus 11.2 months; $P=0.271$ ) and $10 \%$ improvement in PFS
(6.3 versus 5.8 months; $P=0.214$ ) when compared to sbpaclitaxel arm. However, none of these outcome differences achieved statistical significance.

Interesting findings were noted when subgroup analyses was performed based on histology, age, and geographic location. In patients with squamous histology, significantly increased ORR was seen in the nab-paclitaxel versus sbpaclitaxel arm (41\% versus $24 \%$, respectively; $P<0.001){ }^{70,71}$ The superior ORR reported here is one of the highest ever reported ORR in squamous NSCLC. The reason for improved response rate of nab-paclitaxel in squamous NSCLC remains unclear. In patients with non-squamous NSCLC, nab-paclitaxel was found to be as effective as sb-paclitaxel (ORR 26\% versus $25 \%$, respectively; $P=0.808$ ).

OS was not different among the two arms when evaluated in all the study patients. OS within different histological subtypes was also similar within the two treatment groups. Interestingly, patients $>70$ years old $(n=156)$ showed a significantly longer OS with nab-paclitaxel versus sb-paclitaxel (19.9 versus 10.4 months, respectively; $P<0.009) .^{70,72}$ OS was largely similar between the two groups at different centers where this clinical trial was conducted, except for a significant difference noticed in North America. Patients from North America had improved OS when treated with nab-paclitaxel versus sb-paclitaxel (12.7 versus 9.8 months, respectively; $P=0.008$ ).

As summarized in Table 2, the incidence of various toxicities was significantly different between the two arms. Grade 3 or 4 neutropenia was lower in the nab-paclitaxel arm compared to sb-paclitaxel arm (47\% versus 58\%, respectively; $P<0.001 \%$ ). However, febrile neutropenia rates were similar. Moreover, despite higher grade 3 or 4 anemia or thrombocytopenia, these events were manageable (eg, anemia was easily corrected with a single blood transfusion) and without clinically significant sequelae (eg, thrombocytopenia did not lead to increased rates of hemorrhages). Nab-paclitaxel arm was also shown to have fewer cases of grade $3 / 4$ neuropathy, myalgia, and arthralgia when compared to sb-paclitaxel arm. All grade sensory neuropathy was less frequent in nab-paclitaxel arm when compared to sb-paclitaxel arm (46\% versus $62 \%$, respectively; $P<0.001)$. It is unclear if the decreased neuropathy in nab-paclitaxel arm is due to nab-paclitaxel being less neuropathic (due to absence of Cremophor ${ }^{\circledR}$ ), weekly schedule being more favorable, or a combination of both. This study did not utilize a double-blind design and thus has a potential bias in toxicity assessment. The Functional Assessment of Cancer Therapy (FACT)-Taxane questionnaire ${ }^{70}$ was administered to the study participants to assess quality of life. 
Ninety-eight percent completed the questionnaire at baseline and $94 \%$ had follow-up assessment. Nab-paclitaxel was associated with significant improvements in the neuropathy subscale $(P<0.001)$, the pain subscale $(P<0.001)$, and the hearing loss subscale $(P=0.002)$ when compared to the sbpaclitaxel. There were also fewer interruptions in daily life in the nab-paclitaxel arm. While weekly sb-paclitaxel has less toxicity and higher efficacy in breast cancer compared to every 3-week sb-paclitaxel, improved survival has not been demonstrated in NSCLC. NSCLC lacks randomized studies to compare effectiveness between the Socinski Phase III regimen (weekly nab-paclitaxel and carboplatin) versus weekly sb-paclitaxel and carboplatin combination.

\section{Conclusion and future perspective}

$\mathrm{Nab}$-paclitaxel is a novel next generation taxane that uses nanoparticle albumin-bound-technology to enhance the efficacy and safety of conventional paclitaxel. It has a nanoparticle structure and ability to adhere to specific albumin binding receptors in the vascular endothelial cells. These properties allow the delivery of higher doses and increased intratumoral concentration of paclitaxel. There are several practical advantages of nab-paclitaxel over the Cremophor EL ${ }^{\circledR}$-paclitaxel: namely, it circumvents the need to administer corticosteroids or antihistamine premedications for prevention of hypersensitivity reactions, the infusion time is much shorter (30 minutes), and it does not require special equipment like non-PVC infusion systems. A recent Phase III study paved the way to nab-paclitaxel FDA approval as a first-line option in NSCLC. This study showed a favorable risk-benefit ratio in all patients, improved ORR in patients with squamous histology, and superior OS in patients $\geq 70$ years of age. Even though the cumulative dose of paclitaxel was higher in nab-paclitaxel group compared to sb-paclitaxel group, the former was still better tolerated without any premedications. Moreover, the incidence of grade $\geq 3$ neuropathy, a frequent cause of discontinuation or dose reduction in patients receiving taxane chemotherapy, is found to be much lower in nabpaclitaxel (compared to conventional paclitaxel).

Studying the outcomes of nab-paclitaxel in combination with other chemotherapy agents and/or radiation in the frontline setting is also warranted in future clinical trials. Investigators from University of Texas Southwestern medical center are conducting a Phase I/II trial to study the effects of nab-paclitaxel versus sb-paclitaxel (in combination with carboplatin and concurrent radiation) followed by consolidation in stage IIIA/B NSCLC. ${ }^{73}$ The Cancer and Leukemia Group B (CALGB) has completed accrual of patients to a single-arm Phase II study combining nab-paclitaxel and carboplatin as induction regimen followed by radiotherapy and erlotinib in poor risk stage III NSCLC. ${ }^{74}$ In the second-line setting, an ongoing multicenter Phase II study is evaluating the safety and efficacy of weekly nab-paclitaxel in elderly patients with NSCLC. ${ }^{75}$ University of Washington Center Consortium is performing another Phase II study of weekly nab-paclitaxel in advanced NSCLC patients with epidermal growth factor receptor (EGFR) mutations, who already had disease progression with EGFR tyrosine kinase inhibitors. ${ }^{76}$ The effects of albumin-bound paclitaxel in a neoadjuvant setting in NSCLC are also being explored. A group of Chinese investigators is recruiting participants in a stage IIB/IIIA study of squamous NSCLC patients. This trial studies the outcomes of carboplatin combination with nab-versus sb-paclitaxel in a neoadjuvant setting. ${ }^{77}$

Many tumor biomarkers in NSCLC are being studied to explore their predictive value for responsiveness to specific treatments. Several biomarkers such as EGFR exon deletion/mutation, anaplastic lymphoma kinase gene rearrangement, and ROS1 gene rearrangement are recognized to have predictive value for specific targeted agents in NSCLC. These biomarkers are now routinely assessed as they impact treatment decisions. However, no biomarker has been proven to have a predictive value for either paclitaxel or nab-paclitaxel. Multiple biomarkers have been investigated for their potential to predict treatment outcomes with paclitaxel in various malignancies, including NSCLC. Checkpoint gene with forkhead-associated domain and ring finger gene methylation is significantly related to high sensitivity to paclitaxel. ${ }^{78}$ A preclinical study with NSCLC cell lines suggested high ATP binding cassette B1(ABCB1) mRNA expression as a predictive biomarker for poor chemosensitivity to paclitaxel. ${ }^{79}$ High beta-3 tubulin expression is correlated with poor prognosis and resistance to chemotherapy in general, but lacks a specific predictive value for paclitaxel versus gemcitabine. ${ }^{80} \mathrm{~A}$ recent randomized Phase II trial studied the outcome of NSCLC treatment with either ixabepilone or paclitaxel containing regimens when stratified by beta- 3 tubulin. ${ }^{81}$ The results showed no predictive value of beta-3 tubulin in differentiating clinical activity of paclitaxel or ixabepilone containing regimens. These few examples highlight the challenges as well as unmet need in this specific area. As discussed earlier, developing an assay to test for SPARC continues to be fertile ground for research. However, validation of this assay may be difficult due to biological complexities and technical challenges. Future direction in this field warrants further identification and prospective validation of a biomarker that can help identify 
NSCLC patients who would derive the most benefit from nab-paclitaxel.

\section{Disclosure}

The authors report no conflict of interest in this work.

\section{References}

1. Siegel R, Naishadham D, Jemal A. Cancer statistics, 2013. CA Cancer J Clin. 2013;63(1):11-30.

2. Schiller JH, Harrington D, Belani CP, et al. Comparison of four chemotherapy regimens for advanced non-small-cell lung cancer. $N$ Engl J Med. 2002;346(2):92-98.

3. Chu Q, Vincent M, Logan D, Mackay JA, Evans WK; Lung Cancer Disease Site Group of Cancer Care Ontario's Program in Evidence-based Care. Taxanes as first-line therapy for advanced non-small cell lung cancer: a systematic review and practice guideline. Lung Cancer. 2005;50(3):355-374.

4. Stinchcombe TE. Nanoparticle albumin-bound paclitaxel: a novel Cremphor-EL-free formulation of paclitaxel. Nanomedicine (Lond). 2007;2(4):415-423.

5. Gelderblom H, Verweij J, Nooter K, Sparreboom A, Cremophor EL. The drawbacks and advantages of vehicle selection for drug formulation. Eur J Cancer. 2001;37(13):1590-1598.

6. van Zuylen L, Verweij J, Sparreboom A. Role of formulation vehicles in taxane pharmacology. Invest New Drugs. 2001;19(2):125-141.

7. Sparreboom A, van Zuylen L, Brouwer E, et al. Cremophor ELmediated alteration of paclitaxel distribution in human blood: clinical pharmacokinetic implications. Cancer Res. 1999;59(7):1454-1457.

8. Gradishar WJ, Tjulandin S, Davidson N, et al. Phase III trial of nanoparticle albumin-bound paclitaxel compared with polyethylated castor oil-based paclitaxel in women with breast cancer. J Clin Oncol. 2005;23(31):7794-7803.

9. Ibrahim NK, Desai N, Legha S, et al. Phase I and pharmacokinetic study of ABI-007, a Cremophor-free, protein-stabilized, nanoparticle formulation of paclitaxel. Clin Cancer Res. 2002;8(5):1038-1044.

10. Szebeni J, Muggia FM, Alving CR. Complement activation by Cremophor EL as a possible contributor to hypersensitivity to paclitaxel: an in vitro study. J Natl Cancer Inst. 1998;90(4):300-306.

11. Irizarry LD, Luu TH, McKoy JM et al. Cremophor EL-containing paclitaxel-induced anaphylaxis: a call to action. Community Oncol. 2009;6(3):132-134. Available from http://www.oncologypractice.com/ co/journal/articles/0603132.pdf. Accessed November 26, 2013.

12. Chao TC, Chu Z, Tseng LM, et al. Paclitaxel in a novel formulation containing less Cremophor EL as first-line therapy for advanced breast cancer: a phase II trial. Invest New Drugs. 2005;23(2):171-177.

13. Desai N, Trieu V, Yao Z, et al. Increased antitumor activity, intratumor paclitaxel concentrations, and endothelial cell transport of cremophorfree, albumin-bound paclitaxel, ABI-007, compared with cremophorbased paclitaxel. Clin Cancer Res. 2006;12(4):1317-1324. [Erratum appears in Clin Cancer Res. June 15, 2006;12(12):3869 Note: Dosage error in article text].

14. John TA, Vogel SM, Tiruppathi C, Malik AB, Minshall RD. Quantitative analysis of albumin uptake and transport in the rat microvessel endothelial monolayer. Am J Physiol Lung Cell Mol Physiol. 2003;284(1):L187-L196.

15. Minshall RD, Tiruppathi C, Vogel SM, Malik AB. Vesicle formation and trafficking in endothelial cells and regulation of endothelial barrier function. Histochem Cell Biol. 2002;117(2):105-112.

16. Schubert W, Frank PG, Razani B, Park DS, Chow CW, Lisanti MP. Caveolae-deficient endothelial cells show defects in the uptake and transport of albumin in vivo. $J$ Biol Chem. 2001;276(52):48619-48622.

17. Sparreboom A, Scripture CD, Trieu V, et al. Comparative preclinical and clinical pharmacokinetics of a cremophor-free, nanoparticle albuminbound paclitaxel (ABI-007) and paclitaxel formulated in Cremophor (Taxol). Clin Cancer Res. 2005;11(11):4136-4143.
18. Schnitzer JE, Oh P. Antibodies to SPARC inhibit albumin binding to SPARC, gp60, and microvascular endothelium. Am J Physiol. 1992;263(6 Pt 2):H1872-H1879.

19. Trieu V, Hwang J, Zaidi S, et al. SPARC overexpression enhances sensitivity to nab-paclitaxel in vivo. AACR Meeting Abstracts. 2007;2007(1_Annual_Meeting):3480.

20. Shao H, Tang H, Salavaggione OE, et al. Improved response to nab-paclitaxel compared with cremophor-solubilized paclitaxel is independent of secreted protein acidic and rich in cysteine expression in non-small cell lung cancer. J Thorac Oncol. 2011;6(6): 998-1005.

21. Koukourakis MI, Giatromanolaki A, Brekken RA, et al. Enhanced expression of SPARC/osteonectin in the tumor-associated stroma of non-small cell lung cancer is correlated with markers of hypoxia/ acidity and with poor prognosis of patients. Cancer Res. 2003;63(17): $5376-5380$.

22. Sato N, Fukushima N, Maehara N, et al. SPARC/osteonectin is a frequent target for aberrant methylation in pancreatic adenocarcinoma and a mediator of tumor-stromal interactions. Oncogene. 2003;22(32):5021-5030.

23. Brown TJ, Shaw PA, Karp X, Huynh MH, Begley H, Ringuette MJ. Activation of SPARC expression in reactive stroma associated with human epithelial ovarian cancer. Gynecol Oncol. 1999;75(1): 25-33.

24. Suzuki M, Hao C, Takahashi T, et al. Aberrant methylation of SPARC in human lung cancers. Br J Cancer. 2005;92(5):942-948.

25. Desai N, Trieu V, Damascelli B, Soon-Shiong P. SPARC Expression Correlates with Tumor Response to Albumin-Bound Paclitaxel in Head and Neck Cancer Patients. Transl Oncol. 2009;2(2):59-64.

26. Ng SS, Figg WD, Sparreboom A. Taxane-mediated antiangiogenesis in vitro: influence of formulation vehicles and binding proteins. Cancer Res. 2004;64(3):821-824.

27. Ng SS, Sparreboom A, Shaked Y, et al. Influence of formulation vehicle on metronomic taxane chemotherapy: albumin-bound versus cremophor EL-based paclitaxel. Clin Cancer Res. 2006;12(14 Pt 1):4331-4338.

28. Yamashita K, Upadhay S, Mimori K, Inoue H, Mori M. Clinical significance of secreted protein acidic and rich in cystein in esophageal carcinoma and its relation to carcinoma progression. Cancer. 2003;97(10): 2412-2419.

29. Che Y, Luo A, Wang H, Qi J, Guo J, Liu Z. The differential expression of SPARC in esophageal squamous cell carcinoma. Int $J$ Mol Med. 2006;17(6):1027-1033.

30. Wang CS, Lin KH, Chen SL, Chan YF, Hsueh S. Overexpression of SPARC gene in human gastric carcinoma and its clinic-pathologic significance. Br J Cancer. 2004;91(11):1924-1930.

31. Zhao ZS, Wang YY, Chu YQ, Ye ZY, Tao HQ. SPARC is associated with gastric cancer progression and poor survival of patients. Clin Cancer Res. 2010;16(1):260-268.

32. Franke K, Carl-McGrath S, Rohl FW, et al. Differential Expression of SPARC in Intestinal-type Gastric Cancer Correlates with Tumor Progression and Nodal Spread. Transl Oncol. 2009;2(4):310-320.

33. Infante JR, Matsubayashi H, Sato N, et al. Peritumoral fibroblast SPARC expression and patient outcome with resectable pancreatic adenocarcinoma. J Clin Oncol. 2007;25(3):319-325.

34. Watkins G, Douglas-Jones A, Bryce R, Mansel RE, Jiang WG. Increased levels of SPARC (osteonectin) in human breast cancer tissues and its association with clinical outcomes. Prostaglandins Leukot Essent Fatty Acids. 2005;72(4):267-272.

35. Nagai MA, Gerhard R, Fregnani JH, et al. Prognostic value of NDRG1 and SPARC protein expression in breast cancer patients. Breast Cancer Res Treat. 2011;126(1):1-14.

36. Chen J, Wang M, Xi B, et al. SPARC is a key regulator of proliferation, apoptosis and invasion in human ovarian cancer. PloS One. 2012;7(8):e42413.

37. Yamanaka M, Kanda K, Li NC, et al. Analysis of the gene expression of SPARC and its prognostic value for bladder cancer. J Urol. 2001;166(6): 2495-2499. 
38. Massi D, Franchi A, Borgognoni L, Reali UM, Santucci M. Osteonectin expression correlates with clinical outcome in thin cutaneous malignant melanomas. Hum Pathol. 1999;30(3):339-344.

39. Azim HA, Jr., Singhal S, Ignatiadis M, et al. Association between SPARC mRNA expression, prognosis and response to neoadjuvant chemotherapy in early breast cancer: a pooled in-silico analysis. PloS one. 2013;8(4):e62451.

40. Desai NP, Trieu V, Hwang LY, Wu R, Soon-Shiong P, Gradishar WJ. Improved effectiveness of nanoparticle albumin-bound (nab) paclitaxel versus polysorbate-based docetaxel in multiple xenografts as a function of HER2 and SPARC status. Anti-cancer drugs. 2008;19(9):899-909.

41. Delany AM. Matricellular proteins osteopontin and osteonectin/SPARC in pancreatic carcinoma. Cancer Biol Ther. 2010;10(1):65-67.

42. Kris MG, O'Connell JP, Gralla RJ, et al. Phase I trial of taxol given as a 3-hour infusion every 21 days. Cancer Treat Rep. 1986;70(5):605-607.

43. Brown T, Havlin K, Weiss G, et al. A phase I trial of taxol given by a 6-hour intravenous infusion. J Clin Oncol. 1991;9(7):1261-1267.

44. Nyman DW, Campbell KJ, Hersh E, et al. Phase I and pharmacokinetics trial of ABI-007, a novel nanoparticle formulation of paclitaxel in patients with advanced nonhematologic malignancies. $J$ Clin Oncol. 2005;23(31):7785-7793.

45. Stinchcombe TE, Socinski MA, Lee CB, et al. Phase I trial of nanoparticle albumin-bound paclitaxel in combination with gemcitabine in patients with thoracic malignancies. J Thorac Oncol. 2008;3(5):521-526.

46. Abraxane ${ }^{\mathbb{1}}$ (nab-paclitaxel) [package insert]. Summit, NJ: Celgene Corporation; 2013.

47. Sparreboom A, van Tellingen O, Nooijen WJ, Beijnen JH. Nonlinear pharmacokinetics of paclitaxel in mice results from the pharmaceutical vehicle Cremophor EL. Cancer Res. 1996;56(9):2112-2115.

48. van Tellingen O, Huizing MT, Panday VR, Schellens JH, Nooijen WJ, Beijnen JH. Cremophor EL causes (pseudo-) non-linear pharmacokinetics of paclitaxel in patients. Br J Cancer. 1999;81(2):330-335.

49. Henningsson A, Sparreboom A, Sandström M, et al. Population pharmacokinetic modelling of unbound and total plasma concentrations of paclitaxel in cancer patients. Eur J Cancer. 2003;39(8):1105-1114.

50. Rahman A, Korzekwa KR, Grogan J, Gonzalez FJ, Harris JW. Selective biotransformation of taxol to 6 alpha-hydroxytaxol by human cytochrome P450 2C8. Cancer Res. 1994;54(21):5543-5546.

51. Briasoulis E, Pentheroudakis G, Karavasilis V, Tzamakou E, Rammou D, Pavlidis N. Weekly paclitaxel combined with pegylated liposomal doxorubicin (CaelyxTM) given every 4 weeks: dose-finding and pharmacokinetic study in patients with advanced solid tumors. Ann Oncol. 2004;15(10):1566-1573.

52. Fruscio R, Lissoni AA, Frapolli R, et al. Clindamycin-paclitaxel pharmacokinetic interaction in ovarian cancer patients. Cancer Chemother Pharmacol. 2006;58(3):319-325.

53. Tan AR, Dowlati A, Jones SF, et al. Phase I study of pazopanib in combination with weekly paclitaxel in patients with advanced solid tumors. Oncologist. 2010;15(12):1253-1261.

54. Biakhov MY, Kononova GV, Iglesias J, et al. Nab-Paclitaxel in patients with advanced solid tumors and hepatic dysfunction: a pilot study. Expert Opin Drug Saf. 2010;9(4):515-523.

55. Green MR, Manikhas GM, Orlov S, et al. Abraxane, a novel Cremophorfree, albumin-bound particle form of paclitaxel for the treatment of advanced non-small-cell lung cancer. Ann Oncol. 2006;17(8): 1263-1268.

56. Rizvi NA, Riely GJ, Azzoli CG, et al. Phase I/II trial of weekly intravenous 130-nm albumin-bound paclitaxel as initial chemotherapy in patients with stage IV non-small-cell lung cancer. J Clin Oncol. 2008;26(4):639-643.

57. Paik PK, James LP, Riely GJ, et al. A phase 2 study of weekly albuminbound paclitaxel (Abraxane(R)) given as a two-hour infusion. Cancer Chemother Pharmacol. 2011;68(5):1331-1337.

58. Allerton JP, Hagenstad CT, Webb RT, et al. A phase II evaluation of the combination of paclitaxel protein-bound and carboplatin in the first-line treatment of advanced non-small cell lung cancer (NSCLC). $J$ Clin Oncol. 2006;24(Suppl 18):7127.
59. Socinski MA, Manikhas GM, Stroyakovsky DL, et al. A dose finding study of weekly and every-3-week nab-Paclitaxel followed by carboplatin as first-line therapy in patients with advanced non-small cell lung cancer. J Thorac Oncol. 2010;5(6):852-861.

60. Okamoto I, Yamamoto N, Kubota K, et al. Safety and pharmacokinetic study of nab-paclitaxel plus carboplatin in chemotherapy-naive patients with advanced non-small cell lung cancer. Invest New Drugs. 2012;30(3):1132-1137.

61. Reynolds C, Barrera D, Jotte R, et al. Phase II trial of nanoparticle albumin-bound paclitaxel, carboplatin, and bevacizumab in first-line patients with advanced nonsquamous non-small cell lung cancer. J Thorac Oncol. 2009;4(12):1537-1543.

62. Sandler A, Gray R, Perry MC, et al. Paclitaxel-carboplatin alone or with bevacizumab for non-small-cell lung cancer. $N$ Engl $J$ Med. 2006;355(24):2542-2550.

63. Patel JD, Hensing TA, Rademaker A, et al. Phase II study of pemetrexed and carboplatin plus bevacizumab with maintenance pemetrexed and bevacizumab as first-line therapy for nonsquamous non-small-cell lung cancer. J Clin Oncol. 2009;27(20):3284-3289.

64. Casey EM, Harb W, Bradford D, et al. Randomized, double-blinded, multicenter, phase II study of pemetrexed, carboplatin, and bevacizumab with enzastaurin or placebo in chemonaive patients with stage IIIB/IV non-small cell lung cancer: Hoosier Oncology Group LUN06-116. J Thorac Oncol. 2010;5(11):1815-1820.

65. Stevenson JP, Langer CJ, Somer RA, et al. Phase 2 trial of maintenance bevacizumab alone after bevacizumab plus pemetrexed and carboplatin in advanced, nonsquamous nonsmall cell lung cancer. Cancer. 2012;118(22):5580-5587.

66. Reck M, von Pawel J, Zatloukal P, et al. Overall survival with cisplatingemcitabine and bevacizumab or placebo as first-line therapy for nonsquamous non-small-cell lung cancer: results from a randomised phase III trial (AVAiL). Ann Oncol. 2010;21(9):1804-1809.

67. Patel J, Socinski MA, Garon EB, Reynolds CH. A Randomized, Openlabel, Phase 3, Superiority Study Of Pemetrexed (Pem)+Carboplatin (Cb)+Bevacizumab (B) Followed By Maintenance Pem+B Versus Paclitaxel (Pac) $+\mathrm{Cb}+\mathrm{B}$ Followed By Maintenance B In Patients (pts) With Stage IIIB Or IV Non-squamous Non-small Cell Lung Cancer (NSNSCLC). Chicago Multidisiplinary Symposium in Thoracic Oncology. 2012:LBPL 1

68. Ramalingam SS, Dahlberg SE, Langer CJ, et al. Outcomes for elderly, advanced-stage non small-cell lung cancer patients treated with bevacizumab in combination with carboplatin and paclitaxel: analysis of Eastern Cooperative Oncology Group Trial 4599. J Clin Oncol. 2008;26(1):60-65.

69. Riess J, Ho C, Davies AM, et al. Phase I/II trial of combination nab-paclitaxel and pemetrexed in advanced solid tumor patients (pts) with emphasis on non-small cell lung cancer (NSCLC). ASCO Meeting Abstracts. 2013;31(Suppl 15):e19147. Available from http://meetinglibrary. asco.org/content/109989-132. Accessed November 26, 2013.

70. Socinski MA, Bondarenko I, Karaseva NA, et al. Weekly nab-paclitaxel in combination with carboplatin versus solvent-based paclitaxel plus carboplatin as first-line therapy in patients with advanced non-small-cell lung cancer: final results of a phase III trial. J Clin Oncol. 2012;30(17): 2055-2062.

71. Socinski MA, Okamoto I, Hon JK, et al. Safety and efficacy analysis by histology of weekly nab-paclitaxel in combination with carboplatin as first-line therapy in patients with advanced non-small-cell lung cancer. Ann Oncol. 2013;24(9):2390-2396.

72. Socinski MA, Langer CJ, Okamoto I, et al. Safety and efficacy of weekly nab(R)-paclitaxel in combination with carboplatin as first-line therapy in elderly patients with advanced non-small-cell lung cancer. Ann Oncol. 2013;24(2):314-321.

73 University of Texas Southwestern Medical Center. A Phase I/II Study of Nab-Paclitaxel, or Paclitaxel, Plus Carboplatin With Concurrent Radiation Therapy Followed by Consolidation in Patients With Favorable Prognosis Inoperable Stage IIIA/B NSCLC Available from: http:// clinicaltrials.gov/ct2/show/NCT00553462?term $=\mathrm{NCT}+00553462 \&$ ran k=1 NLM identifier: NCT 01757288. Accessed November 18, 2013. 
74. Canver and Leukemia Group B. Carboplatin and Paclitaxel AlbuminStabilized Nanoparticle Formulation Followed by Radiation Therapy and Erlotinib in Treating Patients With Stage III Non-Small Cell Lung Cancer That Cannot Be Removed By Surgery. Available from: http:// clinicaltrials.gov/ct2/show/NCT00553462?term=NCT+00553462\& rank=1 NLM identifier: NCT 00553462. Accessed November 18, 2013.

75. UNC Lineberger Comprehensive Cancer Center. Single arm on the tolerability of weekly nab-paclitaxel. Available from: http://clinicaltrials. gov/ct2/show/NCT01702844?term=NCT+01702844\&rank=1. NLM identifier: NCT 01702844. Accessed November 18, 2013.

76. Fred Hutchinson Cancer Research Center/University of Washington Cancer Consortium. Paclitaxel Albumin-Stabilized Nanoparticle Formulation in Treating Patients With Previously Treated Advanced Non-Small Cell Lung Cancer. Available from: http://clinicaltrials. gov/ct2/show/NCT01620190?term=NCT+01620190\&rank=1. NLM identifier: NCT01620190. Accessed November 18, 2013.

77 The First Affiliated Hospital of Guangzhou Medical University. Neoadjuvant Chemotherapy of Nanoparticle Albumin-bound Paclitaxel/ Carboplatin vs. Paclitaxel/Carboplatin in Stage II B and IIIA Squamous Cell Carcinoma of the Lung. Available from: http://clinicaltrials.gov/ct2/ show/NCT01872403?term $=\mathrm{NCT}+01872403 \&$ rank=1. NLM identifier: NCT01872403. Accessed November 18, 2013.
78. Takeshita M, Koga T, Takayama K, et al. Alternative efficacy-predicting markers for paclitaxel instead of CHFR in non-small-cell lung cancer. Cancer Biol Ther. 2010;10(9):933-941.

79. Meng X, Wang G, Liu P, et al. ATP-binding cassette B1 gene polymorphisms, mRNA expression and chemosensitivity to paclitaxel in nonsmall cell lung cancer cells. Respirology. 2011;16(8):1228-1234.

80. Levallet G, Bergot E, Antoine M, et al. High TUBB3 expression, an independent prognostic marker in patients with early non-small cell lung cancer treated by preoperative chemotherapy, is regulated by K-Ras signaling pathway. Mol Cancer Ther. 2012;11(5):1203-1213.

81. Edelman MJ, Schneider CP, Tsai CM, et al. Randomized phase II study of ixabepilone or paclitaxel plus carboplatin in patients with non-smallcell lung cancer prospectively stratified by beta-3 tubulin status. J Clin Oncol. 2013;31(16):1990-1996.
International Journal of Nanomedicine

\section{Publish your work in this journal}

The International Journal of Nanomedicine is an international, peerreviewed journal focusing on the application of nanotechnology in diagnostics, therapeutics, and drug delivery systems throughout the biomedical field. This journal is indexed on PubMed Central,

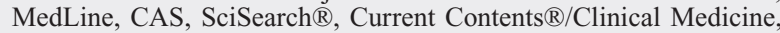

\section{Dovepress}

Journal Citation Reports/Science Edition, EMBase, Scopus and the Elsevier Bibliographic databases. The manuscript management system is completely online and includes a very quick and fair peer-review system, which is all easy to use. Visit http://www.dovepress.com/ testimonials.php to read real quotes from published authors. 